\title{
Residual renal function after partial or radical nephrectomy for renal cell carcinoma
}

\author{
David Chapman, BSc, ${ }^{* *}$ Ron Moore, MD, PhD, FRCSC,; Scott Klarenbach, MD, MSc; ${ }^{*}$ \\ Branko Braam, MD, PhD, FASN"s
}

\begin{abstract}
Renal cell carcinoma (RCC) is often detected incidentally and early. Currently, open partial nephrectomy and laparoscopic total nephrectomy form competing technologies. The former is invasive, but nephron-sparing; the other is considered less invasive but with more loss of renal mass. Traditionally, emphasis has been placed on oncologic outcomes. However, a patient with an excellent oncologic outcome may suffer from morbidity and mortality related to renal failure. Animal models with hypertension and diabetic renal disease indicate accelerated progression of pre-existing disease after nephrectomy. Patients with RCC are older and they have a high prevalence of diabetes and hypertension. The progression of renal failure may also be accelerated after a nephrectomy. Our analysis of the available literature indicates that renal outcomes in RCC patients after surgery are relatively poorly defined. A strategy to systematically evaluate the renal function of patients with RCC, with joint discussion between the nephrologist and the oncologic team, is strongly advocated.
\end{abstract}

\section{Can Urol Assoc J 2010;4(5):337-343}

\section{Résumé}

L'hypernéphrome est souvent décelé fortuitement et au stade précoce. Actuellement, la néphrectomie partielle par voie ouverte et la néphrectomie totale par laparoscopie sont des technologies concurrentes. Tandis que la première est plus invasive, mais permet l'épargne des néphrons, la seconde est moins invasive mais entraîne une perte plus importante de masse rénale. Par le passé, on a mis l'emphase sur les résultats d'un point de vue oncologique. Cependant, un patient pour qui la chirurgie donne d'excellents résultats en matière d'élimination de la tumeur pourrait présenter une morbidité et une mortalité en lien avec une insuffisance rénale. Des modèles animaux de néphropathie avec hypertension et diabète indiquent une évolution accélérée des maladies préexistantes après la néphrectomie. Les patients présentant un hypernéphrome sont plus âgés; la prévalence du diabète et de l'hypertension est élevée. L'évolution de l'insuffisance rénale peut aussi être accélérée après la néphrectomie. Notre analyse des articles publiés montre que les résultats sur le plan de la fonction rénale après une chirurgie pour traiter un hypernéphrome sont relativement mal définis. Une stratégie fondée sur une évaluation systématique de la fonction rénale des patients atteints d'hypernéphrome, avec discussion entre le néphrologue et l'équipe de soins oncologiques, est fortement encouragée.

\section{Introduction}

Renal cell carcinoma (RCC) originates from the proximal tubule of the kidneys and is the most common form of kidney cancer. It accounts for about $85 \%$ of solid renal masses. ${ }^{1}$ Renal cell carcinoma may be difficult to diagnose early, due to its initially asymptomatic nature; however, with advances and increased use of diagnostic imaging, the diagnosis of RCC often occurs early as an incidental finding. Risk factors for RCC include age, obesity, smoking, hypertension, gender, race, long-term dialysis and the presence of particular hereditary diseases, such as von Hippel-Lindau syndrome, hereditary papillary RCC and Birt-Hogg-Dubé syndrome. ${ }^{2}$ The mean age of patients at diagnosis from 14 European cancer centres was 62.8 years; two-thirds of these patients were male. ${ }^{3}$ Correlations exist, for men and women, between increased body mass index (obesity), hypertension and smoking status and the incidence of RCC. ${ }^{1,4}$ There is also a large overlap in risk factors for chronic kidney disease (CKD) and RCC; it is likely that many RCC patients will have reduced renal function or be at risk of rapid progression of CKD. Since more tumours are now found early, many people undergo surgery with excellent oncologic results. For this high-risk group of elderly patients, there is a further decrease in renal function due to surgery; these patients are also at risk of rapidly progressing to end-stage renal disease and needing renal replacement therapy. Moreover, decreased renal function is an independent risk factor for cardiovascular events and all-cause mortality. ${ }^{5}$ Therefore, the treating team has to balance oncologic outcomes with the preservation of renal function; these considerations may influence the choice of surgical strategy.

\section{Assessing kidney function and renal risk factors}

Currently, 3 aspects of renal function are pivotal to assess kidney dysfunction: (1) an estimate of the filtration of the kidney; (2) quantification of proteinuria; and (3) urinalysis. The glomerular function rate (GFR) can be assessed in a number of ways, which are all based on the unique properties of creatinine. One way is to estimate the creatinine clearance by a 24-hour urine collection, and plasma and urine determinations of creatinine. There are inherent limitations with 
this estimation are urine collection errors and, at very low clearances, overestimation of GFR by creatinine secreted into the tubules. Frequently used is the Modified Diet of Renal Disease (MDRD) formula to calculate the GFR of a patient; it uses the age, sex, ethnicity and an equation based on epidemiological data. This method is currently being further refined and developed, ${ }^{6}$ since it was derived from CKD patients and has a limited accuracy in people with a GFR $>60 \mathrm{~mL} / \mathrm{min} / 1.73 \mathrm{~m}^{2}$. The older Cockroft-Gault formula provides an estimated GFR based on plasma creatinine, sex, age and body weight. The gold standard for the measurement of GFR is the inulin infusion technique. Inulin lacks one of the limitations of creatinine, as it is solely filtered. However, since there is some creatinine secretion, this leads to an overestimation of GFR at low levels of renal function. ${ }^{7}$ ${ }^{125}$-lothalamate, ${ }^{51} \mathrm{Cr}$-EDTA or ${ }^{99 \mathrm{~m} T C-D T P A}$ are radioactive markers that can be used in combination with renal imaging to determine (split) GFR. ${ }^{7}$ Finally, there is substantial interest in cystatin C to estimate GFR; however, this has not yet entered clinical practice. For further discussion on the use and limitations of methods to assess estimated GFR, the reader is referred to the review by Stevens and colleagues. ${ }^{7}$

The Kidney Disease Outcomes Quality Initiative (KDOQI) is a classification system used to determine the stage of CKD, which is staged from 1 to 5 based on the estimated GFR; stage 5 is end-stage requiring renal replacement therapy. ${ }^{8}$ Typically, consequences of CKD, such as anemia, acidosis, hyperkalemia and deranged calcium phosphorus balance, become prominent at a GFR of less than $30 \mathrm{~mL} / \mathrm{min} / 1.73 \mathrm{~m}^{2}$ (stage IV renal failure in the KDOQI guidelines). At this threshold, it is typical to have a nephrologist involved in the care of the patient. Proteinuria, initially screened for using a semi-quantitative dipstick approach and refined using an albumin to creatinine ratio in spot urine, is associated with faster progression of CKD. During diagnosis and workup, the patient's electrolytes should be examined for secondary consequences of renal disease, such as hyperkalemia. Urinalysis abnormalities (other than the frequently present hematuria due to the RCC itself) can indicate other co-existing renal conditions. A nuclear scan can determine split renal function.

\section{Surgical considerations}

In the absence of metastatic disease, radical nephrectomy (RN) for RCC, which was popularized by Dr. Charles Robson, has proven to be very efficacious in treating RCC. ${ }^{9}$ However, partial (nephron-sparing) nephrectomy (PN) has been shown to be equally effective for small, localized tumours while preserving significantly greater renal mass post-surgery. ${ }^{10}$ More recently, the size-limit of the tumour is being challenged, ${ }^{11}$ while minimally invasive techniques are being explored. First of all, laparoscopic PN seems safe and effective, albeit specialized training and equip- ment are essential. ${ }^{12}$ From there, cryoablation and radiofrequency ablation have evolved. The procedures can be performed using an open laparotomy, with laparoscopy, but also transcutaneously. Results for cryoablation seem somewhat more promising than for radiofrequency ablation regarding recurrence rates. ${ }^{12}$ Factors that determine the selection of the particular surgical therapy are related to the tumour size, the localization of the tumour within the kidney, the patient's condition and the relevant experience of the physician. There is support to treat T1 (and even T3) tumours preferentially with $\mathrm{PN},{ }^{10,13,14}$ however, the use of $\mathrm{PN}$ is thought to be underutilized..$^{15}$ Even PN is currently being applied for tumours herniating into the renal sinus. ${ }^{16}$ While tumour outcomes are important, the patient's age, overall health, contralateral kidney function and the ability of the remaining kidney to compensate should also be considered, for the acute surgical risks and for the longer-term renal and patient outcomes. There are alarming reports about the very high frequency of renal pathology, particularly glomerulosclerosis, in the non-tumourous tissue of nephrectomy specimens. Bijol and colleagues report a very high incidence of renal abnormalities, with only $25 \%$ of the kidneys showing an entirely normal architecture. ${ }^{17}$ These abnormalities were associated with a more pronounced decrease in renal function after uninephrectomy, compared to patients with normal parenchyma, as could be anticipated from studies in living kidney donors. ${ }^{18}$ Related to the procedure itself, renal artery clamping and renal cooling have been applied to reduce bleeding. There are a number of studies showing that this has no negative impact on renal function. ${ }^{19-21}$ Clamping, cooling and reconstruction are more difficult with laparoscopic procedures, however newer hemostasis techniques and sealants may make it unnecessary to perform these potentially harmful procedures.

\section{How does reduction in renal mass affect renal function in the short and long term?}

A reduction of renal mass (i.e., a decrease in the number of nephrons) is followed by a decrease in renal function. Inevitably, the removal of $50 \%$ of the renal mass by a RN immediately reduces renal function to about half of its prenephrectomy value. However, over a very short time, the remaining contralateral kidney begins to compensate for the loss in renal function. ${ }^{22}$ Along with a decrease in the number of functioning nephrons, and with similar intake of food (salt) and water, these remaining nephrons increase their function to maintain fluid and electrolyte homeostasis. Over time, chronic hyperfiltration, driven partly by an increase in glomerular pressure, will lead to renal damage or an accelerated deterioration of pre-existing renal damage. ${ }^{23}$ These short- and long-term structural and functional adaptations of the remaining renal tissue need to be taken into consideration when 
predicting renal compensation and outcomes.

\section{Functional and structural adaptations}

The GFR can be increased by glomerular pressure and increased filtration coefficient. Principle determinants of glomerular pressure are pre- and post-glomerular resistance, determined by the afferent and efferent arterioles, respectively. Decreasing afferent arteriolar resistance and increasing efferent arteriolar resistance will increase glomerular pressure. The renal vasculature is modulated by several vasoactive peptides including angiotensin II. ${ }^{24}$ The afferent arteriole resistance will be reduced by inhibition of angiotensin II, or by reducing the sympathetic input. ${ }^{25}$ After removal of the renal tissue, GFR of the ipsilateral and/or contralateral kidney need to be increased to maintain fluid and electrolyte balance, through adjustments in vasomotor control of the microvasculature. ${ }^{24}$ Following a nephrectomy, plasma volume will expand due to the decrease in renal excretory function. Consequently, angiotensin II formation is diminished, which will attenuate afferent arteriole tone allowing an increase in glomerular pressure and filtration. Inhibition of reno-renal nerve traffic after nephrectomy will contribute to vasodilatation in the remaining kidney. Finally, adaptations of the tubuloglomerular feedback system are required. Normally, an increase in fluid delivery to the macula densa, will initiate afferent arteriolar vasoconstriction due to activation of the tubuloglomerular feedback (TGF) system. ${ }^{26}$ After the nephrectomy, the TGF system has to allow an increase in GFR in the remaining renal tissue by allowing higher early distal flow rates.

Following a loss in renal mass, the remaining tissue will also attempt to compensate by structural changes that commence immediately. Renal tissue undergoes growth following nephron loss and is the result of both hypertrophy and hyperplasia. Renal hypertrophy is the result of the stimulation of translation in the cell cycle, as well as the suppression of growth inhibitory genes; it occurs early with a greater influence on the compensatory growth compared to hyperplasia. ${ }^{27-29}$ In a healthy organism with healthy kidneys, these adaptations take place without negative consequences for renal function in the long-run, despite the fact that glomerular hypertension and hyperfiltration can cause glomerular damage.

\section{Consequences of experimental reduction in renal mass}

Experimental studies have indicated that renal mass reduction, through a wide range of mechanisms, accelerates the progression of renal disease. Considering diabetic nephropathy, Levine and colleagues reported that there was a significant increase in the ratio of mesangial matrix surface to the glomerular surface, indicative of progressive diabetic nephropathy, in response to nephrectomy..$^{30}$ In a model of spontaneous proteinuric renal failure with mild hypertension (the Fawn-hooded rat), unilateral nephrectomy accelerated proteinuria and glomerulosclerosis compared to a shamoperated control group. ${ }^{31}$ Finally, acceleration of renal injury was shown in obese Zucker rat models. ${ }^{32}$ While these experimental studies cannot be replicated in humans, it is reasonable to assume that similar consequences would occur to subjects with RCC, who are likely to be older and have a high prevalence diabetes, hypertension and obesity. These studies, among dozens of other similar studies in a large variety of models for hypertension, diabetes and kidney disease, illustrate that in a diseased animal (including humans) or an animal where there is already one existing factor, increasing glomerular capillary pressure with a reduction in renal mass is accompanied by an acceleration of renal disease.

\section{Exploring theoretical scenarios for the progression of renal disease after nephrectomy}

Several scenarios can be envisioned about the decline in renal function after nephrectomy. Two basic phenomena determine long-term renal outcome: (1) the reduction in renal function due to the nephrectomy, and (2) the rate of progression of renal disease prior to and after the surgery. A patient with normal renal function undergoing a nephrectomy is depicted in Fig. 1 (part a). As the patient ages, there is an expected decline in GFR prior to the nephrectomy. Compared to the normal age-related decline in GFR, the rate of decline in patients with renal disease is accelerated. Nephrectomy is associated with an acute and significant drop in the GFR, due to the immediate loss of renal mass. From this post-nephrectomy baseline GFR, there are variable rates at which the progression of CKD may occur. Firstly, the reduction of mass could cause an accelerated rate of GFR decline (labelled 1), which leads to a much earlier need for renal replacement therapy and a significant drop in quality of life. Secondly, the decline in GFR may progress at a rate similar to the pre-surgery. Finally, the rate of the decline in GFR may actually become delayed as a result of medications, such as angiotensin-converting enzyme inhibitors, initiated after surgery; these medications may allow the patient to attain renal replacement-free survival to the average life expectancy.

The extent of the renal mass reduction determines the immediate decrease in renal function. Without considering the post-nephrectomy rate of decline, Fig. 1 (part b) depicts the immediate drop in GFR at the time of surgery. The use of $\mathrm{PN}$ indicates a much less severe decrease in GFR following the nephrectomy compared to the RN plot. A more realistic depiction of what may be expected of patient's renal outcomes following a reduction of mass is shown in Fig. 1 (part c). As shown, a more pronounced reduction of mass will result in a greater immediate decline in GFR at the point of 
A

Comparison of decline in GFR of patients with mild CKD and normal age decline prior to nephrectomy

GFR

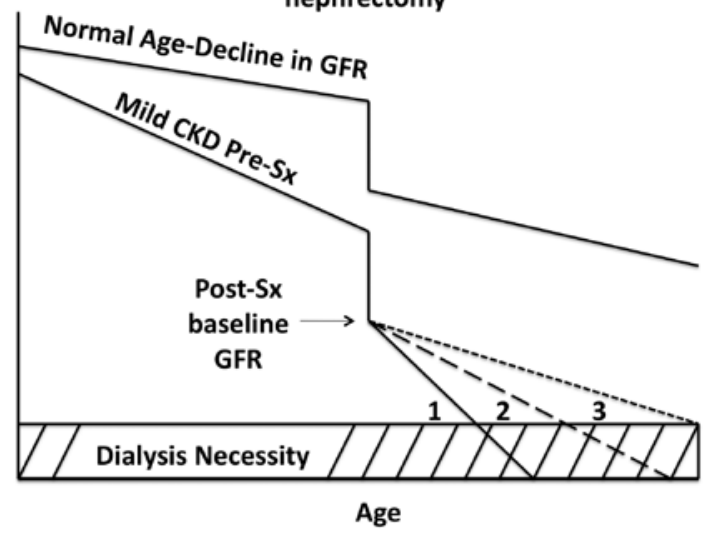

B

Immediate decline in GFR following reduction of mass

(progression is not dependant on the amount of reduction of tissue)

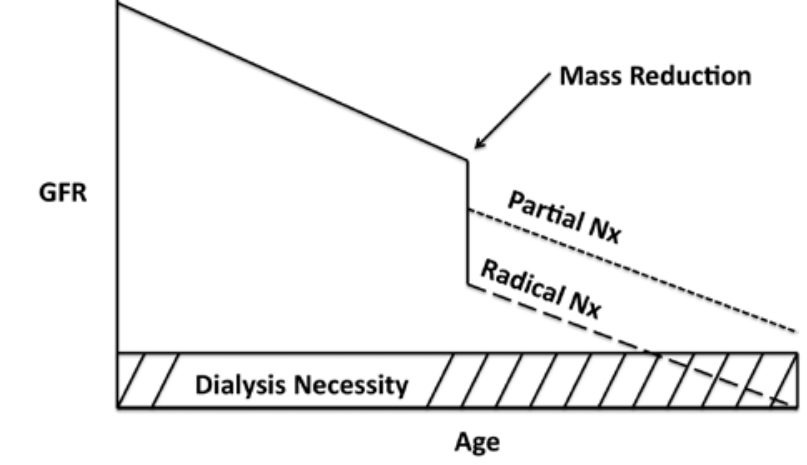

C

GFR decline accelerated by more pronounced reduction in renal mass

GFR

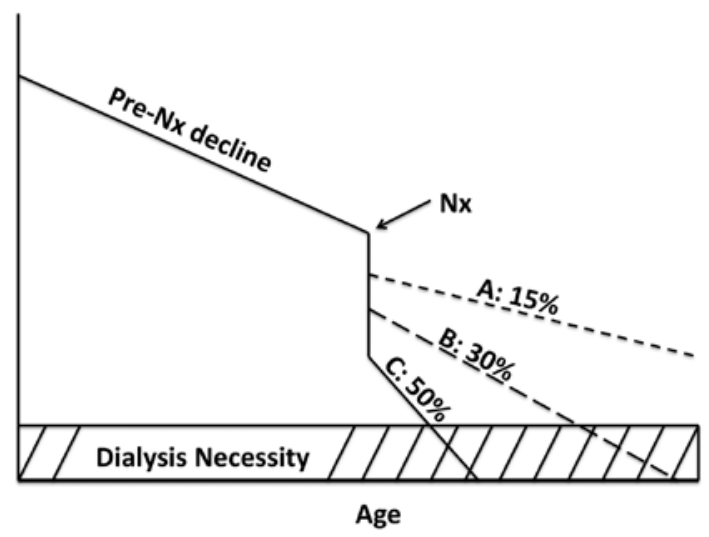

Fig. 1. Different scenarios of progression of CKD following partial and radical nephrectomy. surgery, while also have a significantly accelerated rate of decline in GFR after the procedure. These patients are at the highest risk of reaching end-stage renal disease and requiring renal replacement therapy. As shown, $\mathrm{PN}$, which removes significantly less renal mass, maintains an adequate GFR, and likely comes with a minor acceleration in the decline of the GFR after the nephrectomy. The figure projects the potential outcome of $15 \%$ and $30 \%$ partial reductions, as well as a $50 \%$ radical reduction in renal mass (Fig. 1, part c).

\section{What is known about renal function after nephrectomy in humans?}

Long-term assessment of healthy kidney donors indicate that there is a decrease in creatinine clearance by about $30 \%$ (GFR), a low risk of proteinuria and a negligible risk of developing end-stage renal disease following kidney donation. ${ }^{33}$ The adaptive hyperfunction of the residual kidney after a unilateral nephrectomy has a very rapid onset; effective renal plasma flow has been shown to increase by about $30 \%$ as early as 1 week after surgery and remains elevated for an extended period of time ( $>10$ years). ${ }^{22}$ It was also found that, after surgery, the large remaining renal mass had a greater ability to compensate for the loss. ${ }^{34}$ In 2 recent reports, healthy kidney donors were compared to the general population or matched controls, and were found to have no differences in urinary albumin excretion, GFR, prevalence of hypertension, quality of life, survival and risk of end-stage renal disease over long-term follow-up. ${ }^{35,36}$ On the other hand, meta-analyses have reported higher proteinuria and a post-surgical GFR that was $10 \mathrm{~mL} / \mathrm{min}$ lower than that of the controls, ${ }^{37}$ as well as an increase in blood pressure compared to controls. ${ }^{38}$ It should be noted that living kidney donors are carefully selected and typically younger and generally healthier than the general population and therefore may be expected to have better outcomes than controls. The patients that are diagnosed with RCC are older, may have had a long history of smoking and/or hypertension, may have developed type II diabetes and are more likely to be obese; as such, outcomes after nephrectomy may be materially different.

Patients with T1 tumours, as staged by TNM $(<7 \mathrm{~cm})$, have been found to have greater than a $90 \% 5$-year survival rate, indicating that caregivers should put a greater emphasis on renal outcomes of this patient population. ${ }^{39,40} \mathrm{~A}$ study by Huang and colleagues found that a total of 192 out of 662 patients (29\%) developed a new onset of GFR lower than $60 \mathrm{~mL} / \mathrm{min} / 1.73 \mathrm{~m}^{2}$ and 105 out of 662 patients $(16 \%)$ developed new onset of GFR lower than $45 \mathrm{~mL} / \mathrm{min} / 1.73 \mathrm{~m}^{2}$ following nephrectomy. ${ }^{41}$ This study supports the notion that patients who undergo a $\mathrm{RN}$ have a significantly higher risk of developing moderately severe CKD and therefore may expe- 
rience negative effects on life span and quality of life. To this extent, RN has been found to be associated with decreased overall survival in patients under 65 years old with T1a $(<4 \mathrm{~cm})$ tumours. ${ }^{42}$ When a patient is eligible for both a $\mathrm{PN}$ and a $\mathrm{RN}$, the maintenance of renal function should be highly prioritized to avoid the risk of renal insufficiency after surgery. Lau and colleagues addressed the long-term outcomes on the treatment of unilateral RCC. They report that $22 \%$ and $11.6 \%$ of patients that underwent $\mathrm{RN}$ and $\mathrm{PN}$, respectively, reached chronic renal failure within 10 years following surgery. ${ }^{43}$ Unfortunately, no rate of progression of renal disease was described and the GFR was not estimated. Another such study reports that within months following a $\mathrm{PN}, 7.5 \%$ of patients reached chronic renal failure. ${ }^{44}$ These findings indicate the importance of renal function in patients with RCC; however, the literature in this field is still relatively scarce stressing the need for further studies.

\section{How does decreased renal function affect acute and chronic consequences of treatment for RCC?}

There are several pertinent considerations regarding surgery in patients with moderate to severe renal insufficiency
(KDOQI stage III/IV). These include uremic thrombopathy, renal anemia, a tendency to become fluid overloaded, hyperkalemia and increased susceptibility for infection. Moreover, patients with CKD have an increased risk of developing acute kidney injury perioperatively. Besides these issues surrounding surgery, CKD may limit the application of biologic response modifiers, such as interleukin-2, interferon-alpha ${ }^{45,46}$ and the new tyrosine kinase inhibitors (TKIs). Current TKIs target vascular endothelial growth factor (VEGF) and include sunitinib and sorafenib for healthy and intermediate-risk patients, while temsirolimus (an mTOR inhibitor) is the first-line therapy for patients with high-risk stratification. ${ }^{47,48}$ Bevacizumab is an agent similar to the TKIs, however its mechanism differs as it is an antibody against VEGF. ${ }^{49}$ VEGF is intrinsically involved in the maintenance of the integrity of the glomerular ultrafilter, since it contributes to nitric oxide production. Moreover, VEGF is involved in regulation of vascular tone and blood pressure by acting directly on the blood vessels, and by altering nitric oxide actions in the kidney, where nitric oxide acts as a natriuretic factor. ${ }^{50}$ It is therefore not surprising that the administration of inhibitors of the actions of VEGF is associated with hypertension and proteinuria. This has been reported for sorafenib, sunitinib and temsirolimus. ${ }^{51-54} \mathrm{~A}$ recent review has indi-

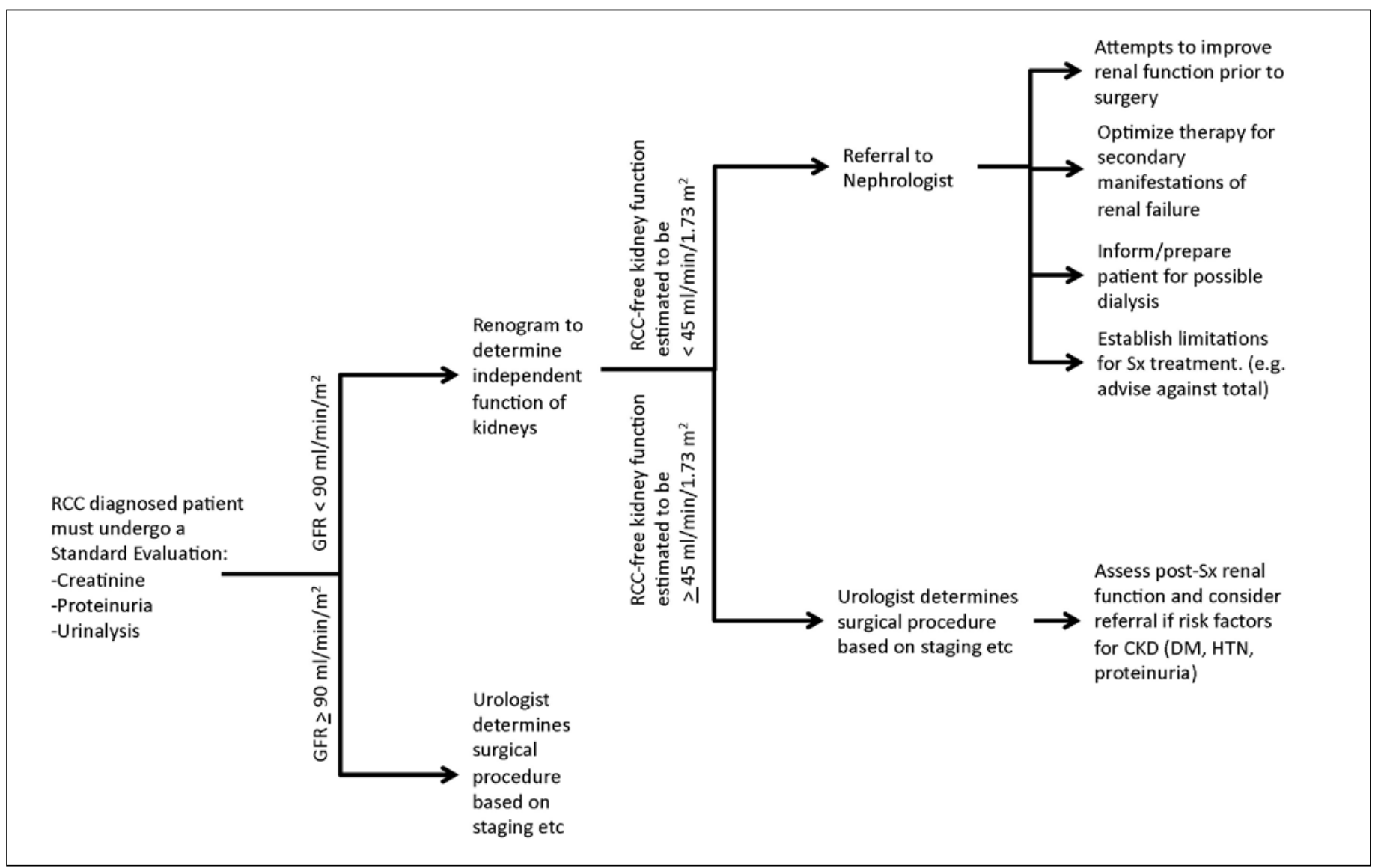

Fig. 2. Proposal for a decision scheme to evaluate renal function and referral to a nephrologist prior to surgery. 
cated that in case of sunitinib to treat RCC, the incidence of renal dysfunction can be as high as $66 \% .{ }^{55}$ Moreover, several cases have now been described where VEGF inhibitors have caused thrombotic microangiopathy. ${ }^{56}$ Although further investigation is required, the current treatment protocols for RCC may introduce a wide array of additional risks to the health of the patient (Table 1).

\section{Summary}

Choosing $\mathrm{RN}$ for a patient with unhealthy and functionally impaired renal tissue may result in severe renal complications immediately or in the long-term; more conservative PN may put the patient at a higher risk of reoccurrence depending on the stage of the tumour. Given the increased detection, earlier stage migration and increasing life expectancy, we suggest a very careful and systematic assessment of the RCC patient with respect to renal function (Fig. 2). The rationale for the threshold of GFR choice is as follows. A GFR $>90 \mathrm{~mL} / \mathrm{min} / 1.73 \mathrm{~m}^{2}$ is considered to be normal. There is currently large dispute about stage III CKD. The general consensus is that the range of GFR from 30 to $60 \mathrm{~mL} /$ $\mathrm{min} / 1.73 \mathrm{~m}^{2}$ is too large; there are proposals being developed to subclassify into IIla (45 to $\left.60 \mathrm{~mL} / \mathrm{min} / 1.73 \mathrm{~m}^{2}\right)$ and IIIb (30 to $45 \mathrm{~mL} / \mathrm{min} / 1.73 \mathrm{~m}^{2}$ ), since the secondary manifestations, such as renal anemia and renal bone disease, typically start to occur below a GFR of $45 \mathrm{~mL} / \mathrm{min} / 1.73 \mathrm{~m}^{2}$, but are absent or very mild with a GFR $>45 \mathrm{~mL} / \mathrm{min} / 1.73 \mathrm{~m}^{2}$. In a case where the initial GFR exceeds $90 \mathrm{~mL} / \mathrm{min} / 1.73 \mathrm{~m}^{2}$, chances are very low that the patient, without complications, will develop a uremic syndrome after nephrectomy. In the case were GFR is below this threshold, CKD complications may occur, particularly if renal function is not symmetrical.

It cannot be overemphasized that the RCC patient, given the age at presentation, will very frequently present with mild to moderate renal dysfunction, and a myriad of risk factors for CKD progression. We advocate for a strategy to develop regional guidelines for the renal evaluation of patients with RCC, which would include a joint discussion between the nephrologist and the oncologic team.

We have identified 2 patient groups diagnosed with RCC that can be further dichotomized. Firstly, we can differentiate between patients with mild to moderate CKD, from those with severe CKD. Patients who have mild to moderate CKD may present with metastatic or non-metastatic disease. Several considerations must be taken for these patients, including the assessment of the severity of renal disease, rate of progression and consequences of a radical nephrectomy. Along with the same considerations as with patients with non-metastatic disease, patients with metastatic disease must also consider the effects of TKIs. Patients with severe CKD are somewhat limited in treatment options. Patients with metastatic disease with severe CKD must consider the consequences of the TK inhibition, as well as consider the acute perisurgical consequences. These patients must also be prepared for hemodialysis following a RN. Last but not least, it should be mentioned that renal failure comes with a very substantial cardiovascular risk. ${ }^{57}$ It should be noted that the overall chance of dying while on dialysis is about $10 \%$ per year. ${ }^{58}$

In this review, we have conveyed concerns about renal function and the surgical treatment of RCC. Although the current TNM staging criteria provide a fairly reliable tool for providing a prognosis to the patient, refinements in the cut-offs of TNM stages can still be made. Ultimately, an adjustment in the tumour staging will increase the number of RCC patients eligible for more conservative PN due to the increase in the number of stage $\mathrm{T} 1$ and $\mathrm{T} 2$ patients.

*Department of Medicine, Division of Nephrology and Immunology, University of Alberta, Edmonton, $A B$; 'Department of Surgery, Division of Urology, University of Alberta, Edmonton, AB; ; Department of Oncology, University of Alberta, Edmonton, AB; \&Department of Physiology, University of Alberta, Edmonton, $A B$

Competing interests: None declared.

Acknowledgements: Dr. Chapman was a recipient of a summer studentship from the Department of Medicine of the University of Alberta Hospital. Dr. Braam is a Heart and Stroke Foundation of Canada New Investigator. Dr. Moore is an Alberta Heritage Foundation for Medical Research (AHFMR) Senior Scholar. Dr. Klarenbach is supported by an AHFMR Population Health Investigator award.

This paper has been peer-reviewed.

\section{References}

1. Setiawan VW, Stram DO, Nomura AM, et al. Risk factors for renal cell cancer: the multiethnic cohort. Am J Epidemiol 2007;166:932-40.

2. Coleman JA. Familial and hereditary renal cancer syndromes. Urol Clin North Am 2008;35:563-72.

3. Karakiewicz Pl, Jeldres C, Suardi N, et al. Age at diagnosis is a determinant factor of renal cell carcinomaspecific survival in patients treated with nephrectomy. Can Urol Assoc J 2008;2:610-7.

4. Bergstrom A, Hsieh CC, Lindblad $\mathrm{P}$, et al. Obesity and renal cell cancer-a quantitative review. Br J Cancer 2001;85:984-90.

5. Hemmelgarn BR, Manns BJ, Lloyd A, et al. Relation between kidney function, proteinuria, and adverse outcomes. JAMA 2010;303:423-9.

6. Levey AS, Stevens LA, Schmid CH, et al. A new equation to estimate glomerular filtration rate. Ann Intern Med 2009;150:604-12.

7. Stevens LA, Levey AS. Measured GFR as a confirmatory test for estimated GFR. J Am Soc Nephrol 2009;20:2305-13

8. National Kidney Foundation. K/DOQI clinical practice guidelines for chronic kidney disease: evaluation, classification, and stratification. Am J Kidney Dis 2002;39:S1-266.

9. Robson CJ, Churchill BM, Anderson W. The results of radical nephrectomy for renal cell carcinoma. J Urol 1969:101:297-301.

10. Nguyen CT, Campbell SC, Novick AC. Choice of operation for clinically localized renal tumour. Urol Clin North Am 2008;35:645-55.

11. Bensalah $\mathrm{K}$, Crepel $M$, Patard JJ. Tumour size and nephron-sparing surgery: does it still matter? Eur Urol 2008; $53: 691-3$ 
Renal function after partial or radical nephrectomy for RCC

12. Hever R, Gill IS, Guazzoni G, et al. A critical analysis of the actual role of minimally invasive surgery and active surveillance for kidney cancer. Eur Urol 2010;57:223-32.

13. Simmons $M N$, Weight CJ, Gill IS. Laparoscopic radical versus partial nephrectomy for tumours $>4 \mathrm{~cm}$ : intermediate-term oncologic and functional outcomes. Urology 2009;73:1077-82.

14. Crepel $M$, Jeldres $C$, Perrotte $P$, et al. Nephron-sparing Surgery Is Equally Effective to Radical Nephrectomy for TIBNOMO Renal Cell Carcinoma: A Population-Based Assessment. Urology Epub 2009 Dec 4.

15. Russo $P$, Huang $W$. The medical and oncological rationale for partial nephrectomy for the treatment of T1 renal cortical tumours. Urol Clin North Am 2008;35:635-43.

16. Lebed B, Jani SD, Kutikov A, et al. Renal Masses Herniating Into the Hilum: Technical Considerations of the "Ball-valve Phenomenon" During Nephron-sparing Surgery. Urology Epub 2009 Oct 24.

17. Bijol V, Mendez GP, Hurwitz S, et al. Evaluation of the nonneoplastic pathology in tumour nephrectomy specimens: predicting the risk of progressive renal failure. Am I Surg Pathol 2006;30:575-84.

18. Ross LF, Thistlethwaite JR Jr. Long-term consequences of kidney donation. N Engl J Med 2009;360:2371; author reply 2372.

19. Kane CJ, Mitchell JA, Meng MV, et al. Laparoscopic partial nephrectomy with temporary arterial occlusion: description of technique and renal functional outcomes. Urology 2004;63:241-6.

20. Bakirtas $H$, Eroglu $M$, Naldoken $S$, et al. Nephron-sparing surgery: the effect of surface cooling and temporary renal artery occlusion on renal function. Urol Int 2009;82:24-7.

21. Kondo $\mathrm{T}$, Nakazawa $\mathrm{H}$, Ito $\mathrm{F}$, et al. Impact of arterial occlusion during partial nephrectomy on residual renal function: an evaluation with (99m)technetium-dimercaptosuccinic acid scintigraphy. Int J Urol 2002;9:43540.

22. Shirasaki Y, Tsushima T, Saika T, et al. Kidney function after nephrectomy for renal cell carcinoma. Urology 2004;64:43-7.

23. Donckerwolcke RM, Coppes MJ. Adaptation of renal function after unilateral nephrectomy in children with renal tumours. Pediatr Nephrol 2001;16:568-74.

24. Carmines PK, Fleming JT. Control of the renal microvasculature by vasoactive peptides. FASEB J 1990;: :3300-9.

25. Denton KM, Luff SE, Shweta A, et al. Differential neural control of glomerular ultrafiltration. Clin Exp Pharmacol Physiol 2004;31:380-6.

26. Komlosi P, Bell PD, Zhang ZR. Tubuloglomerular feedback mechanisms in nephron segments beyond the macula densa. Curr Opin Nephrol Hypertens 2009;18:57-62.

27. Kasinath $B S$, Feliers $D$, Sataranatarajan $K$, et al. Regulation of mRNA translation in renal physiology and disease. Am J Physiol Renal Physiol 2009 Epub 2009 Jun 17.

28. Haysleft JP. Functional adaptation to reduction in renal mass. Physiol Rev 1979;59:137-64.

29. Katz Al, Epstein FH. Relation of glomerular filtration rate and sodium reabsorption to kidney size in compensatory renal hypertrophy. Yale J Biol Med 1967;40:222-30

30. Levine $D Z$, lacovitti M, Robertson SJ. Modulation of single-nephron GFR in the $\mathrm{db} / \mathrm{db}$ mouse model of type 2 diabetes mellitus. II. Effects of renal mass reduction. Am J Physiol Regul Integr Comp Physiol 2008:294:R1840-6.

31. Westenend PJ, Nooyen YA, van der Krogt JA, et al. Functional and structural determinants of glomerulosclerosis in the fawn-hooded rat. Eur I Clin Invest 1992;22:391-5.

32. Kasiske BL, $O^{\prime}$ Donnell MP, Cleary MP, et al. Effects of reduced renal mass on tissue lipids and renal injury in hyperlipidemic rats. Kidney Int 1989;35:40-7.

33. Bieniasz $M$, Domagala $P$, Kwiatkowski $A$, et al. The assessment of residual kidney function after living donor nephrectomy. Transplant Proc 2009;41:91-2.

34. Wilton P, Aperia A, Broberger 0 , et al. Renal compensatory hypertrophy in children with unilateral renal disease. Acta Paediatr Scand 1980;69:83-8.

35. Segev DL, Muzaale AD, Caffo BS, et al. Perioperative mortality and long-term survival following live kidney donation. JAMA 2010;303:959-66.

36. Ibrahim HN, Foley R, Tan L, et al. Long-term consequences of kidney donation. N Engl J Med 2009;360:459-69.
37. Garg AX, Muirhead N, Knoll G, et al. Proteinuria and reduced kidney function in living kidney donors: A systematic review, meta-analysis, and meta-regression. Kidney Int 2006;70:1801-10.

38. Boudville N, Prasad GV, Knoll G, et al. Meta-analysis: risk for hypertension in living kidney donors. Ann Intern Med 2006; 145:185-96.

39. Siemer S, Lehmann J, Loch A, et al. Current TNM classification of renal cell carcinoma evaluated: revising stage T3a. J Urol 2005;173:33-7.

40. Ares Valdes Y. Correlation between symptoms and survival in patients with renal cell carcinoma [in Spanish]. Arch Esp Urol 2009;62:201-6.

41. Huang WC, Levey AS, Serio AM, et al. Chronic kidney disease after nephrectomy in patients with renal cortical tumours: a retrospective cohort study. Lancet Oncol 2006;7:735-40.

42. Thompson RH, Boorijan SA, Lohse CM, et al. Radical nephrectomy for pTla renal masses may be associated with decreased overall survival compared with partial nephrectomy. I Urol 2008;179:468-71.

43. Lau WK, Blute ML, Weaver AL, et al. Matched comparison of radical nephrectomy vs nephron-sparing surgery in patients with unilateral renal cell carcinoma and a normal contralateral kidney. Mayo Clin Proc 2000;75:1236-42

44. Polascik TJ, Pound CR, Meng MV, et al. Partial nephrectomy: technique, complications and pathological findings. J Urol 1995; 154:1312-8.

45. Yagoda A, Abi-Rached B, Petrylak D. Chemotherapy for advanced renal-cell carcinoma: 1983-1993. Semin Oncol 1995;22:42-60.

46. Reeves DJ, Liu CY. Treatment of metastatic renal cell carcinoma. Cancer Chemother Pharmacol 2009;64:11-25

47. Saylor PJ, Michaelson MD. New treatments for renal cell carcinoma: targeted therapies. J Natl Compr Canc Netw 2009;7:645-56.

48. Radulovic S, Bijelogrlic SK. Sunitinib, sorafenib and mTOR inhibitors in renal cancer. J BUON 2007;12(Suppl 1):S151-62.

49. Merseburger AS, Waalkes S, Kuczyk MA. Current state of systemic therapy of metastatic renal cell carcinoma [in German] Urologe A 2009;48:986, 988-9.

50. Braam B. Renal endothelial and macula densa NOS: integrated response to changes in extracellular fluid volume. Am J Physiol 1999;276:R1551-61.

51. Grandinetti CA, Goldspiel BR. Sorafenib and sunitinib: novel targeted therapies for renal cell cancer. Pharmacotherapy 2007;27:1125-44.

52. Theou-Anton N, Faivre $S$, Dreyer $C$, et al. Benefit-risk assessment of sunitinib in gastrointestinal stromal tumours and renal cancer. Drug Saf 2009;32:717-34.

53. Kane RC, Farrell AT, Saber H, et al. Sorafenib for the treatment of advanced renal cell carcinoma. Clin Cancer Res 2006;12:7271-8.

54. Guevremont C, Alasker A, Karakiewicz Pl. Management of sorafenib, sunitinib, and temsirolimus toxicity in metastatic renal cell carcinoma. Curr Opin Support Palliat Care 2009;3:170-9.

55. Zhu X, Stergiopoulos K, Wu S. Risk of hypertension and renal dysfunction with an angiogenesis inhibitor sunitinib: systematic review and meta-analysis. Acta Oncol 2009;48:9-17.

56. Bollee $\mathrm{G}$, Patey N, Cazajous $\mathrm{G}$, et al. Thrombotic microangiopathy secondary to VEGF pathway inhibition by sunitinib. Nephrol Dial Transplant 2009;24:682-5.

57. Al-Ahmad A, Rand WM, Manjunath G, et al. Reduced kidney function and anemia as risk factors for mortality in patients with left ventricular dysfunction. J Am Coll Cardiol 2001;38:955-62.

58. Jaar BG, Coresh J, Plantinga $\mathrm{LC}$, et al. Comparing the risk for death with peritoneal dialysis and hemodialysis in a national cohort of patients with chronic kidney disease. Ann Intern Med 2005; 143:174-83.

Corresponendence: Dr. Branko Braam, University of Alberta Hospital, Department of Medicine/Division of Nephrology and Immunology, 11-132 CSB Clinical Sciences Building Edmonton, AB T6G 2G3; fax: 780-407-7771; braam@ualberta.ca 